\title{
OBSTETRICAL ANAESTHESIA PRACTICE IN THE UNIVERSITY OF TORONTO AFFILIATED HOSPITALS AND SOME RANDOMLY SELECTED COMMUNITY HOSPITALS
}

\author{
Ernest M. Hew, Stephen H. Rolbin, A.F.D. Cole and Susan Virgint
}

\begin{abstract}
A questionnaire was designed to determine the type of personnel that provide obstetrical anaesthesia care and the techniques used in the provision of this care.

All seven hospitals with an obstetrical unit affiliated with the University of Toronto and seven community hospitals responded.

All anaesthetics were given by physicians. Ninety-two per cent of those in University affiliated hospitals and 63 per cent of those in the community hospitals had obtained their specialty qualification.

Standards for preoperative assessment and communication with the patients should be similar to those applied to patients receiving anaesthesia for other reasons. It was clear from our survey that pre-anaesthetic assessment of obstetrical patients differs from that advocated for other surgical patients.

For vaginal deliveries, epidural analgesia was clearly the preferred choice. Subarachnoid block was rarely used. The majority of anaesthetists did not use a test dose. Eleven per cent in University-affliated hospitals and 50 per cent in community hospitals sometimes conducted surgical anaesthesia without tracheal intubation for vaginal delivery. More than 60 per cent routinely encouraged their patients to accept general anaesthesia for Caesarean section. The doctors providing neonatal resuscitation may require further training.

Surveys such as this are important if standards of anaesthetic practice are to be established.
\end{abstract}

KEY WORDS: ANAESTHESIA: obstetrical; pattern of practice.

A QUESTIONNAIRE was designed to determine the pattern of obstetrical anaesthesia practice in all University of Toronto affiliated hospitals and in some randomly selected community hospitals. The questionnaire addressed the following:

(1) The training and experience of anaesthesia personnel;

(2) The standard of pre-operative assessment;

(3) The type of anaesthesia used for vaginal deliveries;

(4) The type of anaesthesia used for Caesarean sections;

(5) The methods used for routine epidural analgesia;

(6) The facilities for and the practice of neonatal resuscitation.

The possible answers for each question were:

Ernest M. Hew, M.D., F.R.C.P.(C), F.F.A.R.C.S.(I), Assistant Professor, Co-Director, Intensive Care Unit; Stephen H. Rolbin, M.D.C.M., F.R.C.P.(C), Co-Director, Obstetrical Anaesthesia; A.F.D. Cole, M.D., F.R.C.P.(C), Co-Director, Obstetrical Anaesthesia; Susan Virgint, R.R.T., Research Technologist, Department of Anaesthesia, Mount Sinai Hospital and University of Toronto.

Address reprint requests to Dr. S. Rolbin, Department of Anaesthesia, Mount Sinai Hospital, 600 University Avenue, Toronto, Ontario MSG 1XS.

Canad. Anaesth. Soc. J., vol. 28, no. 2, March 1981 always, usually, sometimes, rarely or never. The data presented refer to the percentage of anaesthetists who answered "always or usually" to each of the questions.

All seven hospitals with an obstetrical unit at the University of Toronto and seven of nine community hospitals responded to the questionnaire. One hundred and fifty-three anaesthetists were surveyed and 84 replied ( 56 per cent). All replies were anonymous and hence we cannot determine if the remaining anaesthetists did not want their patterns of practice analyzed or whether they did not practice obstetrical anaesthesia. Forty-eight of 91 anaesthetists surveyed in the University affiliated hospitals responded, as did 37 of 62 anaesthetists surveyed in community hospitals. Since there were 27,502 births in 1977 in the hospitals surveyed, the responses permit us to draw some conclusions as to the pattern of obstetrical anaesthesia practice.

\section{Anaesthesia Personnel}

Ninety-two per cent of those in University affiliated and 63 per cent of those in community hospitals had obtained specialty qualification (Table I). University affiliated hospitals tended to 58 
TABLE I

Training of Personnel Administering Anaesthesia for Obstetrics, Percentage Replies*

\begin{tabular}{lrc}
\hline \hline & Affiliated & Community \\
\hline Fellows of Royal College & & \\
Yes & 92 & 63 \\
No & 4 & 17 \\
Year of Graduation & & \\
1970- & 17 & 3 \\
1960-69 & 28 & 29 \\
1950-59 & 38 & 34 \\
before 1950 & 11 & 14 \\
Medical School Training in & & \\
Canada & 51 & 43 \\
U.K. & 23 & 20 \\
U.S. & 0 & 0 \\
Other & 13 & 17 \\
Residency Training in & & \\
Canada & 81 & 74 \\
U.S. & 4 & 3 \\
U.K. & 28 & 14 \\
Other & 9 & 3 \\
Anaesthesia Experience outside Canada & & \\
U.S.A. & 6 & 3 \\
U.K. & 29 & 22 \\
Other & 15 & 25 \\
\hline
\end{tabular}

* Does not add up to 100 per cent because some anaesthetists did not reply to every question.

have more recent graduates. Most were trained in Canada or the United Kingdom.

\section{Pre-Anaesthetic Assessment}

It is clear from our survey that the preoperative assessment of obstetrical patients differs from that of other surgical patients. For example, 10 to 30 per cent of anaesthetists did not introduce themselves, explain what epidural analgesia is, or obtain the mother's consent before inducing epidural analgesia for routine labour and delivery. In addition, 46 per cent did not take a history before administering epidural analgesia.

\section{Comment}

It is generally agreed that preoperative assessment is an important, if not essential, part of anaesthetic management of any patient. ${ }^{1}$ This principle is apparently not applied to obstetrical patients.

\section{ANaesthesia for Vaginal Deliveries}

\section{(a) Techniques}

Only 12 per cent of anaesthetists used oral antacids routinely. Epidural analgesia was the pre- dominant choice for normal vaginal deliveries. Continuous lumbar epidural was the technique always or usually used by 74 per cent of anaesthetists in university affiliated hospitals and 23 per cent in community hospitals. Single dose lumbar epidural analgesia was preferred by $26 \mathrm{per}$ cent in affiliated and by 77 per cent in community hospitals. No anaesthetist considered general anaesthesia with inhalation agents or intravenous drugs the method of choice for vaginal delivery.

Some of the practical details of the technique for epidural analgesia are shown in Table II. Nearly everyone wore a cap, mask and gloves when administering epidural analgesia, but only 60 per cent in affiliated hospitals and 37 per cent in comminity hospitals scrubbed and gowned for an epidural. Most anaesthetists started epidurals in the delivery room. The majority of anaesthetists tried to obtain some analgesia during the second stage of labour (Table II). Only 11 per cent deliberately withheld analgesia.

Eleven per cent of anaesthetists at university affiliated hospitals and 54 per cent in community hospitals sometimes conducted general anaesthesia without tracheal intubation. Thirty-one per cent of all surveyed at some time during their 
TABLE II

Normal Vaginal Delivery Routine for Epidural Administration, Percentage Replying "Always or Usually"

\begin{tabular}{lcc}
\hline \hline & Affiliated & Community \\
\hline $\begin{array}{l}\text { When is continuous epidural started? } \\
\text { according to degree of cervical dilation? }\end{array}$ & 36 & 48 \\
$\quad$ depending on severity of labour pain? & 64 & 52 \\
When establishing an epidural, do you: & & \\
$\quad$ wear cap, mask and gloves & 98 & 100 \\
scrub and gown & 60 & 37 \\
Start epidural in: & & \\
Labour Room & 10 & 38 \\
$\quad$ Delivery Room & 90 & 62 \\
In the second stage of labour, do you: & & \\
$\quad$ withhold analgesia & 11 & 15 \\
provide mild analgesia & 52 & 63 \\
provide deep analgesia & 37 & 22 \\
\hline
\end{tabular}

TABLE III

Use of Test Dose Normal Vaginal Delivery, Percentage Replying "Always or USUally",

\begin{tabular}{lcc}
\hline \hline & Affiliated & Community \\
\hline Single dose Epidural & 14 & 17 \\
Continuous Epidural & 45 & 43 \\
Volume of test dose: & & \\
$2 \mathrm{ml}$. & 50 & 33 \\
$3 \mathrm{ml}$. & 21 & 33 \\
$4 \mathrm{ml}$. & 29 & 11 \\
$5 \mathrm{ml}$ or more & 0 & 22 \\
How long after test dose do you wait? & & \\
2 minutes or less & 38 & 44 \\
3 to 5 minutes & 28 & 44 \\
5 minutes or greater & 38 & 12 \\
\hline
\end{tabular}

career have had at least one patient who developed aspiration pneumonitis associated with obstetrical anaesthesia.

A test dose was not commonly used as part of the epidural technique (Table III). When it was used, both the dose and "waiting time" varied widely.

\section{Comment}

In the authors' opinions it is not necessary to scrub and gown. Experience over 25 years and approximately 75,000 epidurals support our belief. ${ }^{2.3}$ In addition, we feel that it is equally safe to induce an epidural block in the labour room, provided that equipment and drugs necessary for management of complications are immediately available.

The wide variation in technique when a test dose is used is possibly explained by lack of agreement on the need for and method of doing the test. This is reflected by $S$ cott, who recently has questioned the necessity of a test dose. ${ }^{4}$

\section{(b) Choice of Agent}

In university affiliated hospitals, bupivacaine was used by 92 per cent of anaesthetists for the first stage of labour. Eight per cent used mepivacaine. Nineteen per cent used these drugs with epinephrine. In community hospitals, 82 per cent used bupivacaine, 10 per cent used lidocaine and eight per cent used mepivacaine.

For delivery, lidocaine was used to provide pain relief by 86 per cent of anaesthetists.

\section{Comment}

It is of interest that eight per cent of anaes- 
TABLE IV

anaesthesia for Breech and Twin Presentations Methods Used, Percentage RESPONDING "Always OR USUALly"

\begin{tabular}{|c|c|c|c|c|}
\hline & \multicolumn{2}{|c|}{ Affiliated } & \multicolumn{2}{|c|}{ Community } \\
\hline & Breech & Twin & Breech & Twin \\
\hline Pudendal Block & 2 & 0 & 3 & 3 \\
\hline Paracervical block & 0 & 2 & 0 & 0 \\
\hline \multicolumn{5}{|c|}{$\begin{array}{l}\text { Inhalation or Intravenous Analgesia } \\
\text { for delivery under local nerve block }\end{array}$} \\
\hline infiltration or pudendal & 0 & 0 & 9 & 0 \\
\hline Single dose epidural & 16 & 7 & 36 & 30 \\
\hline Continuous epidural & 65 & 74 & 24 & 39 \\
\hline Double catheter technique & 5 & 5 & 0 & 0 \\
\hline Subarachnoid block & 0 & 0 & 0 & 0 \\
\hline General anaesthesia for delivery & 2 & 2 & 13 & 23 \\
\hline \multicolumn{5}{|l|}{ Standby only for potential } \\
\hline resuscitation & 30 & 30 & 13 & 22 \\
\hline
\end{tabular}

*Adds up to $>100$ because several responses possible.

thetists will use mepivacaine for the first stage of labour. Mepivacaine has been shown to accumulate in the mother with repeated doses 5 and to have a longer half-life in the newborn. ${ }^{6}$

Epinephrine, even in the low doses used with local anaesthetics, may cause prolonged labour, ${ }^{7.8}$ adverse maternal systemic effects, ${ }^{9}$ and in the pregnant ewe has been shown to reduce uterine blood flow. ${ }^{10.11}$ We believe the addition of epinephrine is unnecessary in obstetrical anaesthesia because of the relatively long dura. tion of bupivacaine.

Lidocaine is presumably chosen for its rapid onset, although it is said to cause "alert but floppy" babies. ${ }^{12}$ This latter effect led the American College of Obstetricians and Gynaecologists and the American Academy of Paediatrics to recommend in 1978 that the use of lidocaine and mepivacaine be avoided in obstetrics. ${ }^{13}$ The anaesthetists surveyed are either unaware of this recommendation, or do not feel that the evidence is sufficiently strong. Further investigations are necessary to clarify this question.

\section{(c) Breech and Twin Presentations}

The anaesthetic techniques used are presented in Table IV. It appeared that epidural analgesia was well accepted for those obstetric difficulties.

\section{(d) Accidental Dural Puncture}

If dural puncture occurred during administration of a single-dose epidural, 58 per cent of anaesthetists in affiliated hospitals and 65 per cent in community hospitals would carry on with a subarachnoid block. During a continous epidural, three per cent would carry on with a subarachnoid block, 87 per cent would make the epidural injection at another interspace and ten per cent would abandon the procedure.

\section{(e) Epidural Blood Patch}

Only 64 per cent of anaesthetists in affiliated and 30 per cent in community hospitals would do an epidural "blood patch" for severe persistent "spinal headache."

\section{Comment}

Recent data have shown the epidural blood patch to be 97 per cent effective and relatively risk-free in the treatment of persistent "spinal headache", 14.15 while there is evidence that prophylactic "blood patches" are not effective. ${ }^{16}$ Comparison of epidaral saline injection with epidural blood patch for the treatment of postlumbar puncture headache clearly demonstrates that the use of a blood patch is far superior. ${ }^{17}$

\section{ANAESTHESIA For CAESAREAN SECTION}

\section{(a) Preoperative Preparation}

If regional analgesia was used, 32 per cent of anaesthetists gave oral antacids routinely. When general anaesthetics were used, oral antacids were given to 59 per cent of elective and 75 per cent of emergency patients.

More than 60 per cent of anaesthetists routinely encouraged patients to accept general anaesthesia for elective or emergency Caesarean section.

Twenty per cent of anaesthetists did not re- 
TABLE $\mathrm{V}$

Technique of General anaesthesia Elective Caesarean Section, Percentage Responding "Always or Usually"

\begin{tabular}{lcc}
\hline \hline & Affiliated & Community \\
\hline Supine Position & 57 & 68 \\
Preoxygenation & 89 & 59 \\
Prehydrate & 45 & 17 \\
Prepare and drape mothers before induction & 60 & 42 \\
Pretreat with non-depolarizing muscle & 85 & 65 \\
$\quad$ relaxant & 89 & 90 \\
Intubate with succinylcholine & & 10 \\
Intubate with pancuronium or curare as the & 11 & 38 \\
$\quad$ sole muscle relaxant & 69 & 100 \\
Cricoid pressure & 100 & \\
Intubation of Trachea &
\end{tabular}

\section{TABLE VI}

General Anaesthesia for Caesarian Section Choice of Agents before Delivery: Percentage of Anaesthetists that Give 90 to 100 Percent of Their Patients the following Drugs

\begin{tabular}{lcc}
\hline \hline & Affiliated & Community \\
\hline Induction & & \\
$\quad$ Thiopentone & 100 & 89 \\
Ketamine & 0 & 0 \\
Maintenance & & \\
$\mathrm{N}_{2} \mathrm{O}$ greater than $60 \%$ & 58 & 74 \\
$\mathrm{~N}_{2} \mathrm{O}$ less than $60 \%$ & 42 & 26 \\
Halothane & 15 & 3 \\
Methoxyflurane & 2 & 3 \\
Enflurane & 6 & 0 \\
Muscle Relaxants & & \\
Succinylcholine & 81 & 73 \\
Curare & 65 & 3 \\
Pancuronium & 8 & 27 \\
\hline
\end{tabular}

quire blood to be typed and cross matched before an elective Caesarean section and less than 30 per cent held cross matched blood in the delivery room.

\section{Comment}

The authors agree with Crawford that all patients due to have a Caesarean section should be typed and cross matched for two units of blood, which are then kept in the delivery room. ${ }^{18}$ Ideally, a technician should be available in hospital to type and cross match blood for obstetrical emergencies.

\section{(b) General Anaesthesia}

A significant percentage of anaesthetists did not always preoxygenate the lungs, prehydrate with 500 to $1000 \mathrm{ml}$ of intravenous fluid, or pre- pare and drape the patient before induction of anaesthesia (Table V). Most anaesthetists did not use lateral tilt.

Thiopentone was the induction agent of choice with the occasional use of ketamine (Table VI). More than half of the anaesthetists used more than 60 per cent nitrous oxide before the birth of the baby. Few anaesthetists reduced the concentration of nitrous oxide and replaced it with a volatile agent.

The technique used for emergency Caesarean sections was similar to that used in elective Caesarean sections.

(c) Epidural Anaesthesia

Fifty-eight per cent in affiliated hospitals and 43 per cent in community hospitals prehydrated their patients. Similar percentages were seen for 
TABLE VII

Epidural Analgesia for Elective Caesarian Section Choice of local anaesthetic, Percentage Responding "Always or Usually"

\begin{tabular}{lcc}
\hline & Affiliated & Community \\
\hline Lidocaine $\mathrm{HCL}-2 \%$ & 34 & 26 \\
Lidocaine $\mathrm{CO}_{2}-2 \%$ & 16 & 21 \\
Mepivacaine-2\% & 20 & 24 \\
Bupivacaine-0.5\% & 30 & 18 \\
Bupivacaine-0.75\% & 0 & 3 \\
Other (e.g. mixtures) & 0 & 8 \\
Addition of Epinephrine & 17 & 15 \\
\hline
\end{tabular}

the use of lateral tilt, administration of oxygen to the mother, and electrocardiographic monitoring.

The choice of local anaesthetic is outlined in Table VII. There was no clear favourite among the agents used. As for vaginal deliveries, there is similar controversy concerning the addition of epinephrine.

\section{Comment}

It is of interest that most anaesthetists do not use lateral tilt despite its proven value in avoiding aortocaval compression. ${ }^{19,22}$ Potent volatile agents are not widely used during general anaesthesia even though they have been shown to improve the condition of the neonate without increasing maternal complications. ${ }^{23.24}$ We have no explanations as to why these techniques are not used routinely. ${ }^{25}$

(d) Fathers in the Caesarean Section Room

Thirty-three per cent of anaesthetists in affiliated and six per cent in community hospitals permitted fathers in the delivery room.

\section{Comment}

It is not clear whether this practice represents personal belief of the anaesthetists or hospital policy.

\section{(e) Use of Vasopressors}

Only 62 per cent of anaesthetists in affiliated and 71 per cent of those in community hospitals used vasopressors if hypotension persisted. Of these anaesthetists 20 per cent in affiliated and 85 per cent in community hospitals used agents that cause uterine vasoconstriction. The remaining anaesthetists would not use vasopressors in these circumstances.

\section{Comment}

Persistent maternal hypotension (systolic less than 100 torr or 20 per cent less than baseline 26 ) for five to seven minutes or longer may lead to foetal distress. ${ }^{27}$ Hypotension remains a common complication of regional anaesthesia. ${ }^{28}$ When it is transient, there are usually no foetal complications. ${ }^{28}$ The management of maternal hypotension includes further uterine displacement, acute intravenous volume expansion, and administration of oxygen. ${ }^{28}$

In the past vasopressors have not been used because of fear of uterine vasoconstriction and, thus, foetal hypoxia. In the sheep, uterine blood flow is only minimally affected by ephedrine or mephentermine (Wyamine ${ }^{\circledR}$ ). ${ }^{29}$ This is in contrast to other vasopressors such as methoxamine (Vasoxyl( $\left.{ }^{(}\right)$, phenylephrine (Neosynephrine ${ }^{(7)}$ ), metaraminol (Aramine ${ }^{\circledR}$ ), ${ }^{29}$ and dopamine (Intropin $^{\text {(8) }} .^{30}$ Ephedrine or mephensermine should be given if severe hypotension persists for longer than one or two minutes.

\section{NEWBORN RESUSCITATION}

\section{(a) Monitoring and Patterns of Practice}

Fifty per cent of anaesthetists in affiliated and 38 per cent of those in community hospitals monitored the newborn's temperature. Less then ten per cent monitored the electrocardiogram or blood pressure during resuscitation.

Twenty-five per cent in university affiliated hospitals would not apply external cardiac compression in spite of bradycardia of $60 / \mathrm{min}$ or less in a newborn despite "adequate resuscitation". Most centres had the capability of establishing an intravascular line if needed. However, only 30 per cent of anaesthetists played a role in establishing the umbilical artery or venous line, or a peripheral venous line. Fifty per cent of anaes- 
TABLE VIII

Neonatal Resuscitation Role of Paediatricians vs. Anaesthetists, Percentage Responding AfFirmatively

\begin{tabular}{lcc}
\hline & Affiliated & Community \\
\hline $\begin{array}{l}\text { Can you adequately monitor the mother and } \\
\text { resuscitate the child? }\end{array}$ & 30 & 47 \\
$\begin{array}{l}\text { Should another M.D. be available for either } \\
\text { the resuscitation or for the maternal } \\
\text { anaesthetic? }\end{array}$ & 80 & 60 \\
What is the ideal role of an anaesthetist in \\
resuscitation of the newborn? \\
$\begin{array}{l}\text { 1. Anaesthetist is in charge and works } \\
\text { with paediatrician }\end{array}$ \\
$\begin{array}{l}\text { 2. Anaesthetist should hand over } \\
\text { responsibility for care of infant when } \\
\text { paediatrician arrives or if he is present }\end{array}$ \\
$\begin{array}{l}\text { 3. Anaesthetist is responsible for } \\
\text { respiratory support and monitoring, } \\
\text { paediatrician is responsible for } \\
\text { establishing intravascular lines, } \\
\text { monitoring and treatment of haemo- } \\
\text { dynamic status }\end{array}$ \\
\hline
\end{tabular}

thetists in affiliated and 70 per cent in community hospitals administered drugs to the newborn.

\section{(b) Role of Paediatricians vs. Anaesthetists}

Most anaesthetists did not feel that they can adequately monitor the mother and resuscitate the infant at the same time (Table VIII). They would welcome another doctor to help with the resuscitation of the newborn or with the anaesthetic for the mother. Fifty-nine per cent in affiliated and 67 per cent in community hospitals felt that the ideal role for the anaesthetist is that of the physician-in-charge of newborn resuscitation, working with and utilizing the skills of paediatricians.

\section{Comment}

The importance of newborn resuscitation in the delivery room cannot be over-emphasized. A French cost-benefit study states that one of the best and certainly most cost-effective methods of preventing perinatal death and major morbidity is immediate resuscitation of the neonate. ${ }^{31}$

One of the main advantages of hospital over home births is the presence of personnel and facilities for neonatal resuscitation should this be required. Ideally, a doctor competent in neonatal resuscitation should attend all births. The doctors involved in neonatal resuscitation may require further training. Our aim should be to discourage "home births" where the obstetrician, general practitioner or midwife is usually unable to carry out adequate resuscitation of either the mother or baby.

\section{Discussion}

Previously only a few surveys have assessed the training of residents and the practice of obstetrical anaesthesia in the United States ${ }^{32}$ and Britain. ${ }^{33}$ Our study is the first to document anaesthetic methods and techniques used by Canadian anaesthetists. We have attempted to document the pattern of practice in the University of Toronto affiliated hospitals and some randomly selected community hospitals. We did not assess the factors which influence the pattern of practice. We believe that some of the practices documented are good, while others are not.

Our study does not allow any conclusion concerning maternal or perinatal mortality or morbidity.

The inconsistent use of accepted techniques such as left uterine displacement by lateral tilt, the failure to use vasopressurs despite persistent hypotension, the reliance on general anaesthesia for Caesarean section are of great interest. New scientific knowledge takes time to become incorporated into medical practice. This might be a factor in some of the practices described.

Surveys such as the one described must be conducted if an attempt is to be made to establish standards for anaesthetic practice. In addition, the factors which determine the patterns of prac- 
tice need to be assessed. Only by proceeding in this manner could one hope to assess and thus improve anaesthetic practice.

\section{ACKNOWLEDGEMENTS}

The assistance of Miss Rosemary O'Connor in preparing this manuscript is gratefully acknowledged.

\section{REFERENCES}

1. The Committee on Standards of Practice of the Canadian Anaesthetists' Society. Guidelines for the Minimal Standards of Practice of Anaesthesia (1977).

2. Eisen, S.M., Rosen, N., Winesanker, H., et al. The Routine Use of Epidural Anaesthesia in Obstetrics: A clinical Review of 9,532 Cases. Can. Anaesth. Soc. J. 7: 280-289 (1960).

3. Hellman, K. Epidural Anaesthesia in Obstetrics: A Second Look at 26,127 Cases. Can. Anaesth. Soc. J. 12: 398-404 (1965).

4. Scotr, D.B. Mendelson's Syndrome. Editorial in Br. J. Anaesth. 50: 977-978(1978).

5. Moore, D.C., Bridenaaugh, L.D., Bagdi, P.A., et al. Accumulation of Mepivacaine Hydrochloride during Caudal Block. Anesthesiology 29: 585-588 (1968).

6. Brown, W.U., Bell, G.C., Lurie, A.O., et al. Newborn Levels of Lidocaine and Mepivacaine in the First Postnatal Day Following Maternal Epidural Anaesthesia. Anesthesiology 42: 698-707 (1977).

7. Joupilla, P., Joupilla, R., KaAR, K., et al. Fetal Heart Rate Patterns and Uterine Activity after Segmental Epidural Anaesthesia. Br. J. Obstet. Gynaecol. 84: 481-486 (1977).

8. Zador, G. \& Nilsson, B.A. Low Dose Intermittent Epidural Anaesthesia with Lidocaine for Vaginal Delivery. II. Influence of Labour and Foetal Acid-Base Status. Acta Obstet. Gynaecol. Scand. (Supp.) 34: 17-30 (1974).

9. Aвouleish, E. Pain Control in Obstetrics. First ed. Philadelphia: J.B. Lippincott Co, 1977, pp 92.

10. Rosenfeld, C.R., Barton, M.D. \& Meschia, G. Effect of Epinephrine on Distribution of Blood Flow in the Pregnant Ewe. Am. J. Obstet. Gynecol. 124: 156-163 (1976).

11. Wallis, K.L., ShNider, S.M., Hicks, J.S., et al. Epidural Anaesthesia in the Normotensive Pregnant Ewe. Anesthesiology 44: 481-487 (1976).

12. Scanlon, J.W., Brown, W.U., Weiss, J.B., et al. Neurobehavioural Responses of Newborn Infants after Maternal Epidural Anaesthesis. Anesthesiology 40: 121-128 (1974).

13. The Committee on Drugs of the American Academy of Paediatrics and the Committee on Obstetrics: Maternal and Fetal Medicine of the American College of Obstetricians and Gynecologists. Effect of Medication during Labour and Delivery on Infant Outcome. Pediatrics 62: 402-403 (1978).

14. Abouleish, E., de la Vega, S., Blendiger, L., et al. Long-term Follow-up of Epidural Blood Patch. Anesth. Analg. 54: 459-463 (1975).

15. Ostheimer, G.W., PAlahniuk, R.J. \& ShNider, S.M. Epidural Blood Patch for Post-lumbar Puncture Headache. Anesthesiology 4I: 307-308 (1974).

16. Palahniuk, R.J. \& Cumming, M. Prophylactic Blood Patch does not Prevent Post-Lumbar Puncture Headache. Can. Anaesth. Soc. J. 26: 132-133 (1979).

17. Bart, A.J., Wheeler, A.S. Comparison of Epidural Saline Placement and Epidural Blood Placement in the Treatment of Postlumbar Puncture Headache. Anesthesiology 48: 221-223 (1978).

18. Crawford, J.S. Principles and Practice of Obstetric Anaesthesia. Fourth ed. Oxford, England: Blackwell Scientific Publications, 1978, pp. 248.

19. ScotT, D. B. Inferior Vena Caval Occlusion in Late Pregnancy, Clinical Anesthesia. Ed. G. Marx. Vol. 10-2. Philadelphia: FA Davis, 1973, pp. 37-50.

20. Bieniarz, J., Crottogin 1, J.J., Curuchet, E., el al. Aortocaval Compression by the Uterus in Late Human Pregnancy: II. An Arteriographic Study. Am. J. Obstet. Gynecol. 100: 203-217 (1968).

21. Crawford, J.S., Burton, M. \& Davies, P. Anaesthesia for Section: Further Refinements of a Technique. Br. J. Anaesth. 45: 726-732 (1973).

22. Datta, S., Alper, M.H., Ostheimer, G.W., et al. Effects of Maternal Position on Epidural Anesthesia for Caesarean Section, Acid-Base Status, and Bupivacaine Concentrations at Delivery. Anesthesiology 50: 205-209 (1979).

23. Molr, D.D. Anaesthesia for Caesarean Section: An Evaluation of a Method Using Low Concentrations of Halothane and 50 per cent of Oxygen. Br. J. Anaesth. 42: 136-142 (1970).

24. Palahniuk, R.J., Scatliff, J., Biehl, D., et al. Maternal and Neonatal Effect of Methoxyflurane, Nitrous Oxide and Lumbar Epidural Anaesthesia for Caesarean Section. Can. Anaesth. Soc. J. 24: 586-596(1977)

25. Crawford, J.S. Principles and Practice of Obstetric Anaesthesia. Fourth ed. Oxford, England: Blackwell Scientific Publications, 1978, pp. 243-284.

26. Abouleish, E. Pain Control in Obstetrics. First ed. Philadelphia: J.B. Lippincott Co, 1977, pp. 103- 104.

27 Hon, E.H., Reid, B.L. \& Hehre, F.W. The Electronic Evaluation of the Fetal Heart Rate. II. Changes with Maternal Hypotension. Am. J. Obstet. Gynecol. 79: 209-215 (1960).

28. Ralston, D.H., \& Shnider, S.M. The Fetal and Neonatal Effects of Regional Anaesthesia in Obstetrics. Anesthesiology 48: 34-64 (1978).

29. Ralston, D.H., Shnider, S.M. \& delorimier, A.A. Effects of Equipotent ephedrine, metaraminol, mephentermine and methoxamine on uterine blood flow in the pregnant ewe. Anesthesiology 40: 354-370 (1974),

30. Rolbin, S.H., Levinson, G., Shnider, S.M. $e t$ al. Dopamine Treatment of spinal hypotension decreases uterine blood flow in the pregnant ewe. Anesthesiology 5I: 36-40 (1979).

31. Chapalain, M.T. Perinatality: French costbenefit studies and decisions on handicap and pre- 
vention in Major Mental Handicap: Methods and Cost of Prevention. CIBA Foundation Symposium. No. 59. Elsevier-Excerpta Medica, North Holland, Amsterdam. 1978, 193-204.

32. Hicks, J.S., Levinson, G. \& Shnider, S.M. Obstetric Anaesthesia Training Centers in the U.S.A. (1975). Anesth. Analg. 55: 839-845 (1976).
33. Crawford, J.S. \& OpIr, L.J. A Survey of the Anaesthetic Services to Obstetrics in the Birmingham Hospital Region. Anaesthesia 31: 56-59 (1976).

\section{RÉSUMÉ}

Dans le but d'identifier le type du personnel qui administrait l'anesthésie obstétricale et les techniques utilisées à cet effet, on a distribué un questionnaire auquel ont répondu tous les hôpitaux affiliés à l'Université de Toronto qui possédaient un département d'obstétrique et sept hôpitaux communautaires.

Toutes les anesthésies obstétricales étaient administrées par des médecins dont quatrevingt douze pour cent possédaient des qualifications de spécialiste dans les hôpitaux universitaires et soixante-trois pour cent dans les hôpitaux communautaires.

Les standards reconnus en usage pour l'évaluation pré-anesthésique et les communications avec les patients devraient être les mêmes pour tous les patients qui reçoivent l'anesthésie; or, il devint évident que l'évaluation pré-anesthésique des parturientes différait de celle qu'on exige pour les autres patients.

Pour les accouchements, l'anesthésie de choix a été l'anesthésie péridurale alors que l'anesthésie sous-arachnoidienne était rarement utilisée. La majorité des spécialistes n'employaient pas de dose-test. Lors d'anesthésie générale pour accouchement, le trachée n'a pas été intubée dans onze pour cent des hôpitaux affiliés à l'Université et dans cinquante pour cent des hôpitaux communautaires. Plus de soixante pour cent des anesthésistes ont suggéré à leurs patientes d'accepter l'anesthésie générale pour la césarienne. Les médecins qui pratiquaient la réanimation néonatale avaient besoin de formation plus avancée.

Des enquêtes comme celle-ci sont importantes si on veut maintenir à un niveau élevé les standards d'exercise de l'anesthésie. 